\title{
QUALIDADE DE SEMENTES DE MILHO DEBULHADAS COM DIFERENTES TEORES DE UMIDADE E FLUXOS DE ALIMENTAÇÃO ${ }^{1}$
}

\author{
CLEVERSON SILVEIRA BORBA, RAMIRO VILELA DE ANDRADE, JOÃO TITO DE AZEVEDO \\ E ANTÓNIO CARLOS DE OLIVEIRA ${ }^{2}$
}

\begin{abstract}
RESUMO - Sementes do milho híbrido simples BR 201 fêmea, debulhadas mecanicamente com diferentes fluxos de alimentação e diversos teores de umidade, foram avaliadas quanto ao dano mecânico, germinação e vigor, imediatamente e após cinco e dez meses de armazenamento. A debulha de sementes do milho híbrido simples BR 201 fêmea, efetuada com a debulhadora da marca D'Andrea modelo $10 \mathrm{HP}$, permitiu chegar às seguintes conclusões: a qualidade das sementes debulhadas não é afetada pelos fluxos de alimentação; a germinação e o vigor são menos afetados quando as sementes são debulhadas com menores teores de umidade; a debulha mecânica deve ser realizada quando as sementes atingirem a faixa de 10 e $15 \%$ de umidade; o dano mecânico reduz drasticamente a qualidade da semente durante $o$ armazenamento.
\end{abstract}

Termos para indexação: Trilha, dano mecânico, germinação, vigor, armazenamento.

\section{QUALITY OF MAIZE SEEDS SHELLED \\ WITH DIFERENT MOISTURE CONTENT AND FEEDING RATES}

\begin{abstract}
Corn seeds of single hybrid BR 201 female were shelled with diferent feeding rates and severals moisture contents. It was analysed mechanical damage, germination and vigor immediately and after storage. The results showed that threshing seeds with a thresher machine D'Andrea model $10 \mathrm{HP}$ there was no effect of feeding rate on seed quality and the germination and vigor were less affected when the seeds were threshed with low moisture content, the threshing should be made when the seeds reach moisture between 10 and $15 \%$ and the mechanical damage reduced drastically seed quality during storage.
\end{abstract}

Index terms: Threshing, mechanical damage, germination, vigor, storage.

\section{INTRODUÇÃO}

A debulha mecânica é um procedimento dos mais importantes no processamento de sementes de milho, devido aos danos mecânicos que podem ocorrer e comprometer a qualidade fisiológica das sementes. $\mathrm{O}$ impacto, a abrasão e o cisalhamento que normalmente ocorrem por ocasião da debulha, constituem fatores altamente deletérios à qualidade das sementes de milho, causando de imediato, danos físicos, queda na germinação e no vigor, podendo ocorrer, também danos internos que mesmo não sendo visíveis, podem afetar a qualidade das sementes, durante $o$ armazenamento.

Bunch (1960), estudando a relação entre umidade e dano mecânico no processamento de sementes de milho, verificou que sementes processadas com teores de umidade de $14,0 \%$, $16,0 \%$ e $18,0 \%$ foram menos danificadas que aquelas com teores de umidade de $8,0 \%, 10,0 \%, 12,0 \%$ e $20,0 \%$, indicando uma possível faixa de uma umidade, favorável à debulha mecânica, para aquelas variedades estudadas.

Chowdhury e Buchele (1975) investigando o efeito de parâmetros operacionais de uma debulhadora com cilindro debulhador pneumático, verificaram que $o$ índice de danos

\footnotetext{
${ }^{1}$ Aceito para publicação em 11/11/94.

Trabalho financiado pela FAPEMIG.

${ }^{2}$ Pesquisadores do Centro Nacional de Pesquisa de Milho e Sorgo da EMBRAPA. Caixa Postal 151 - CEP 35701-970 - Sete Lagoas - MG.
}

dos grãos aumentou com o aumento do teor de umidade, pressão do pneumático e rotação do cilindro debulhador. Por outro lado, Hall \& Johnson (1970) estudando em condições de laboratório, a debulha mecânica de sementes de milho, reportaram que a germinação foi de $59,2 \%, 68,4 \%, 17,0 \%$, $27,9 \%$ e $28,8 \%$ quando as sementes foram debulhadas com grau de umidade em $36 \%, 32 \%, 29 \%, 23 \%, 17 \%$ e $10 \%$, respectivamente, mostrando que quanto menor o teor de umidade das sementes, menor a germinação das sementes debulhadas mecanicamente.

Gomez e Andrews (1971) verificaram que para três lotes de sementes com $11,7 \%, 23,0 \%$ e $40,0 \%$ de danos mecâni$\cos$, o teste inicial de germinação não mediu efetivamente a qualidade das sementes e que o "teste de frio" foi o método mais eficiente para predizer o efeito dos danos mecânicos no tempo potencial de armazenamento das sementes. Concluíram também que os lotes de sementes danificados mecanicamente, tiveram reduzidos drasticamente $o$ vigor e a viabilidade após armazenamento.

Borba et al. (1992) utilizando uma debulhadora estacionária, verificaram que para a obtenção de sementes de alta qualidade, do híbrido simples BR 201 fêmea, as melhores velocidades do cilindro debulhador foram de $400 \mathrm{rpm}$ e 500 $\mathrm{rpm}$, quando os graus de umidade foram de $22,0 \%, 15,0 \%$ e $10,0 \%$. As sementes debulhadas com $10 \%$ de umidade, suportaram melhor as velocidades mais altas do cilindro debulhador. 
Casini (1992) ressaltou que a susceptibilidade à danos mecânicos é uma característica genética herdável, e que em geral, os grãos mais compactos e duros são os menos susceptíveis a dano climático e a ataque de fungos.

Como pode ser visto acima, a combinação do teor de umidade, velocidade do cilindro debulhador e característica genética pode influir na ocorrência de danos mecânicos e na qualidade fisiológica das sementes, mas, além destes fatores e embora não haja informações anteriores, suspeita-se de que o fluxo de alimentação da debulhadora também possa influir na extensão do dano mecânico. O presente trabalho teve como objetivo, determinar o efeito da debulha mecânica na qualidade das sementes do milho híbrido BR 201 fêmea, com diferentes teores de umidade e fluxos de alimentação da debulhadora, antes e após o armazenamento.

\section{MATERIAL E MÉTODOS}

Sementes do milho híbrido simples BR 201 fêmea, provenientes de uma única lavoura, foram debulhadas utilizando-se a debulhadora estacionária da marca D'Andrea modelo $10 \mathrm{HP}$, com velocidade de debulha constante de $533 \mathrm{rpm}$. Sementes debulhadas manualmente foram utilizadas como testemunha. Na debulha mecânica utilizou-se fluxos de alimentação da debulhadora de 25,50 e $75 \mathrm{sacos} / \mathrm{h}$, quando as sementes apresentavam 25\%,18,8\%, $16,5 \%$ e $10,9 \%$ de umidade. Estes tratamentos, constituíram um fatorial $4 \times 4 \mathrm{e}$ foram distribuídos em um delineamento experimental inteiramente casualizado com quatro repetições. Após a debulha as sementes classificadas na peneira 18 foram analisadas quanto ao teor de umidade, dano mecânico, germinação e vigor. O teor de umidade das sementes foi determinado conforme prescrevem as Regras para Análise de Sementes (Brasil, 1992). Para avaliar os danos mecânicos latentes, foi realizada uma análise de germinação e vigor imediatamente e após os 5 e 10 meses de armazenamento. A avaliação de dano mecânico foi realizado com a análise de duas amostras de 100 sementes, as quais após coloridas com o corante "fast green fcf", para facilitar a análise visual, foi determinado a porcentagem de sementes danificadas. As sementes foram consideradas danificadas quando apresentaram no mínimo alguns dos seguintes tipos de danos: sementes quebrada, partida e com trincas no embrião. A germinação foi determinada conforme prescrevem as Regras para Análise de Sementes (Brasil, 1992). O vigor foi determinado através do teste de "envelhecimento acelerado", conforme preconizado por Zink (1968).

\section{RESULTADOS E DISCUSSÃO}

Sementes debulhadas mecanicamente com os fluxos de alimentação de debulhadora de 25,50 e 75 sacos/hora apresentaram porcentagens de danos mecânicos acima de 95,0\% e não diferiram significativamente entre si. Em média apre- sentaram dano de $96,0 \%$ independentemente dos níveis de umidade estudados, e diferiram, significativamente, da debulha manual que apresentou dano de apenas $4,5 \%$ em média (Tabela 1). Estas altas porcentagem de dano mecânico revelaram que a debulhadora necessita ter sua rotação do cilíndro debulhador reduzida, com a troca de polias, já que não existe regulagem da rotação. Por outro lado o formato retangular dos "marteletes"do cilíndro debulhador, dotado de quinas pontiagudas, provavelmente, contribuíram para as causas de altos índices de dano mecânico. $\mathrm{O}$ teor de umidade na debulha, assim como a interação entre teor de umidade e fluxo de alimentação não apresentaram efeitos significativos.

Não houve diferenças significativas entre os fluxos de alimentação, para a germinação e vigor das sementes, nas diferentes faixas de umidade e períodos de armazenamento. Verificaram-se, no entanto, diferenças significativas, entre a debulha manual e a debulha mecânica, representada pela média dos diferentes fluxos de alimentação, na maioria dos casos (Tabela 2).

Observou-se de acordo com a Tabela 2 que a germinação das sementes logo após a colheita foi afetada significativamente pela debulha mecânica, nas umidades de $25,0 \%$ e $18,8 \%$, com decréscimos de $15,6 \%$ e $13,5 \%$, respectivamente, em relação a debulha manual. Quando a debulha mecânica foi realizada com as sementes apresentando umidades de $16,5 \%$ e $10,9 \%$, não houve diferenças significativas entre os porcentuais de germinação das sementes debulhadas. A germinação das sementes, nesses teores de umidade, e avaliadas logo após a colheita, não foi prejudicada. Estes resultados coincidiram com aqueles encontrados por Borba et al. (1992) e Chowdhury \& Buchele (1975), embora estes últimos tenham trabalhado com índices "programados" de danos. Entretanto, diferiram dos resultados encontrados por Bunch (1960) e Hall \& Johnson (1970), provavelmente devido ao fato desta cultivar ter uma característica genética que promove maior resistência ao dano mecânico, conforme observa Casini (1992).

Sementes armazenadas durante os períodos de 5 e 10 meses apresentaram comportamentos semelhantes com relação a germinação, ou seja houve diferenças significativas entre as porcentagens de germinação das sementes debulhadas manual e mecanicamente, com exceção da debulha das sementes com $10,9 \%$ de umidade cujas diferenças não foram significativas. (Tabela 2). Com base nesses resultados verificou-se que, a debulha mecânica não deverá prejudicar a germinação, quando as sementes forem debulhadas com uma umidade em torno de $10,9 \%$. É importante ressaltar, no entanto, que o armazenamento provocou queda siginificativa no porcentual de germinação das sementes quando debulhadas manual ou mecanicamente em todas as umidades.

A Tabela 3 mostra o efeito da debulha mecânica sobre o vigor das sementes em diferentes teores de umidade e períodos de armazenamento. Observou-se que a debulha mecâni- 
ca provocou queda significativa no vigor das sementes em todos os níveis de umidade e períodos de armazenamento. Sementes debulhadas mecanicamente e avaliadas logo após a colheita apresentaram porcentagens de vigor variando de $52,9 \%$ na umidade de $25,0 \%$, a $73,7 \%$ na umidade de $10,9 \%$. Nos casos onde as sementes foram debulhadas mecanicamente e armazenadas, a porcentagem máxima de vigor foi de apenas $41,6 \%$, obtida para o período de 5 meses de armazenamento com porcentagem de umidade de $10,9 \%$.

TABELA 1. Dano mecânico (\%) de sementes com diferentes teores de umidade, debulhadas manual e mecanicamente, pela debulhadora D'Andrea 10 HP, em diferentes fluxos de alimentação, do milho híbrido simples BR 201 fêmea. EMBRAPA/CNPMS, Sete Lagoas, MG 1993.

\begin{tabular}{lcccc}
\hline \multirow{2}{*}{ Umidade (\%) } & $\begin{array}{c}\text { Testemunha } \\
\text { (debulha manual) }\end{array}$ & \multicolumn{2}{c}{$\begin{array}{c}\text { Fluxo de alimentação } \\
\text { (sacos/hora) }\end{array}$} \\
\cline { 2 - 5 } & & 25 & 50 & 75 \\
\hline 25,0 & 4,2 & 96,2 & 98,4 & 97,1 \\
18,8 & 4,2 & 97,9 & 97,0 & 95,1 \\
16,5 & 7,2 & 96,8 & 94,6 & 96,2 \\
10,9 & 2,3 & 96,4 & 92,6 & 94,5 \\
\hline Média & $4,5 \mathrm{a}$ & $96,8 \mathrm{~b}$ & $95,6 \mathrm{~b}$ & $95,7 \mathrm{~b}$ \\
\hline
\end{tabular}

Médias seguidas da mesma letra não diferem significativamente, ao nível de $5 \%$ de probabilidade, pelo teste de Duncan.

TABELA 2. Germinação (\%) de sementes debulhadas manual e mecanicamente com a debulhadora D'Andrea $10 \mathrm{HP}$ com diversos teores de umidade, imediatamente após a debulha e após 5 e 10 meses de armazenamento. EMBRAPA/ CNPMS. Sete Lagoas, MG. 1993

\begin{tabular}{clccc}
\hline \multirow{2}{*}{$\begin{array}{c}\text { Umidade } \\
(\%)\end{array}$} & Debulha & \multicolumn{3}{c}{ Período de armazenamento (meses) } \\
\cline { 3 - 5 } & & 0 & 5 & 10 \\
\hline \multirow{2}{*}{25,0} & manual & $94,5 \mathrm{a}$ & $82,8 \mathrm{a}$ & $85,0 \mathrm{a}$ \\
& mecânica* & $78,9 \mathrm{~b}$ & $63,5 \mathrm{~b}$ & $59,2 \mathrm{~b}$ \\
\multirow{2}{*}{18,8} & manual & $97,5 \mathrm{a}$ & $91,0 \mathrm{a}$ & $89,0 \mathrm{a}$ \\
& mecânica* & $84,0 \mathrm{~b}$ & $71,9 \mathrm{~b}$ & $71,0 \mathrm{~b}$ \\
\multirow{2}{*}{16,5} & manual & $94,2 \mathrm{a}$ & $91,8 \mathrm{a}$ & $86,3 \mathrm{a}$ \\
& mecânica* & $89,7 \mathrm{a}$ & $76,5 \mathrm{~b}$ & $72,5 \mathrm{~b}$ \\
\multirow{2}{*}{10,9} & manual & $94,5 \mathrm{a}$ & $86,8 \mathrm{a}$ & $85,0 \mathrm{a}$ \\
& mecânica* & $93,1 \mathrm{a}$ & $84,7 \mathrm{a}$ & $79,9 \mathrm{a}$ \\
\hline
\end{tabular}

*Média dos fluxos de alimentação.

Médias seguidas com a mesma letra, em coluna e em cada nível de umidade, não se diferem significamente, ao nível de $5 \%$ de probabilidade pelo teste $\mathrm{F}$.
TABELA 3. Vigor (\%) de sementes debulhadas manual e mecanicamente com a debulhadora D'Andrea $10 \mathrm{HP}$, com diversos teores de umidade, imediatamente após a debulha e após 5 e 10 meses de armazenamento. EMBRAPA/CNPMS. Sete lagoas, MG. 1993.

\begin{tabular}{|c|c|c|c|c|}
\hline \multirow{2}{*}{$\begin{array}{c}\text { Umidade } \\
(\%)\end{array}$} & \multirow{2}{*}{ Debulha } & \multicolumn{3}{|c|}{ Período de armazenamento (meses) } \\
\hline & & 0 & 5 & 10 \\
\hline \multirow{2}{*}{25,0} & manual & $88,0 \mathrm{a}$ & $63,3 a$ & $55,0 \mathrm{a}$ \\
\hline & mecânica* & $52,9 \mathrm{~B}$ & $16,0 \mathrm{~b}$ & $9,9 b$ \\
\hline \multirow{2}{*}{18,8} & manual & $92,0 a$ & $78,8 \mathrm{a}$ & $60,0 \mathrm{a}$ \\
\hline & mecânica* & $50,9 b$ & $26,7 b$ & $17,8 b$ \\
\hline \multirow{2}{*}{16,5} & manual & $88,3 a$ & $71,8 \mathrm{a}$ & $66,5 \mathrm{a}$ \\
\hline & mecânica* & $61,5 b$ & $30,8 b$ & $21,7 b$ \\
\hline \multirow{2}{*}{10,9} & manual & $91,0 \mathrm{a}$ & $64,3 a$ & $67,5 a$ \\
\hline & mecânica* & $73,7 b$ & $41,6 b$ & $34,1 \mathrm{~b}$ \\
\hline
\end{tabular}

*Média dos fluxos de alimentação

Médias seguidas com a mesma letra, em coluna e em cada nível de umidade, não se diferem significamente, ao nível de $5 \%$ de probabilidade pelo teste $\mathrm{F}$.

Sementes debulhadas mecanicamente com menores graus de umidade apresentaram maiores porcentuais de germinação e vigor, independentemente do período de armazenamento. $\mathrm{O}$ decréscimo verificado no porcentual de germinação foi de $1,04 \%$, a cada aumento de $1,0 \%$ na umidade das sementes, quando essas foram analisadas logo após a colheita e 1,51\%, quando armazenadas durante 5 meses. Para o vigor, esses decréscimo variou de $1,53 \%$ a $1,81 \%$ (Figuras 1 e 2). Observou-se ainda que as sementes avaliadas logo após a colheita apresentaram maiores porcentuais de germinação e vigor, em relação às sementes armazenadas, em todos os níveis de umidade.

Os resultados obtidos para a germinação e o vigor mostraram com bastante evidência, o efeito negativo dos danos mecânicos no potencial de armazenamento das sementes. Resultados semelhantes foram encontrados por Gomes \& Andrews (1971), ficando evidenciado assim a necessidade de se evitar ao máximo, ocorrência de danos mecânicos, sob pena do lote de sementes perder sua qualidade fisiológica durante 0 armazenamento.

\section{CONCLUSÕES}

A debulha de sementes do milho híbrido simples BR 201 fêmea, efetuada com a debulhadora da marca D'Andrea modelo $10 \mathrm{HP}$, permitiu chegar às seguintes conclusões:

- A qualidade das sementes debulhadas não é afetada pelos fluxos de alimentação.

- A germinação e o vigor são menos afetados quando as 
sementes são debulhadas com menores teores de umidade.

- A debulha mecânica deve ser realizada quando as sementes atingirem entre 10 e $15 \%$ de umidade.

- O dano mecânico reduz drasticamente a qualidade da semente durante 0 armazenamento.

\section{REFERÊNCIAS}

BORBA, C. S.; ANDRADE, R. V.; AZEVEDO, J. T.; OLIVEIRA, A. C. Efeito da debulha mecânica na qualidade de sementes de milho (Zea mays L.). 1992. Revista Brasileira de Sementes, 1994. (No prelo).

BRASIL, Ministério da Agricultura. Regras para Análise de Sementes. Brasília, MA-SNAD-LANARV, 1992. 365p.
BUNCH, H. D. Relationship between moisture content of seed end mechanical damage in seed conveying. Seed World, 86: 14$17,1960$.

CASINI, C. Cosecha anticipada y secado. In: Maiz - Cosecha, Secado y Almacenamiento. Cuaderno de actualization tecnica n $^{\circ}$. 10. INTA. Manfredi (Cordoba) AR. 40p. 1992.

CHOWDHURY, M.H. \& BUCHELE W. F. Effects of the operating parameters of the rubber roller sheller. Transactions of the ASAE, 18(3):482-490, 1975.

GOMEZ, F. \& ANDREWS, C.H. Influence of mechanical injury on seed corn quality. Agronomy Abstract. New York, N. Y. p.43. 1971.

HALL, E.G. \& JOHNSON, W. H. Kernel crackage induced by mechanical shelling. Transactions of the ASAE, 13(1):51-55, 1970.

ZINK, E. Vigor em sementes de milho. In: SEMINÁRIO BRASILEIRO DE SEMENTES, 2. Pelotas, 1968. Anais... p.231232. 1968. 